\title{
PARATHYROID CARCINOMA
}

\author{
Ajit Singh Khurana', Manish Munjal' ${ }^{2}$ Manish Narad ${ }^{3}$
}

Primary parathyroid carcinoma is one of the rare causes of primary hyperparathyroidism. The overall incidence of primary hyperparathyroidism is reported to be one in every 1000 persons. Parathyroid carcinoma accounts for $1 \%$ of all cases of primary hyperparathyroidism (Obara et al 1997).

$80-85 \%$ have a single adenoma (Heath et al 1980). The signs and symptoms of parathyroid carcinoma are renal stones, bone pains, osteoporosis, abdominal pain and weight loss. Physical examination may reveal a cervical mass on palpation. The biochemical abnormalities are elevated serum calcium levels with concomitently elevated parathyroid hormone levels. A case of parathyroid carcinoma is being presented because of its rarity, and the therapeutic modality adopted.

\section{CASE REPORT}

A 35 years old male presented in Dayanand Medical College and Hospital, Ludhiana with the under mentioned picture, recurrent renal calculi for the last 9 years, pain abdomen which was vague and generalised for the last 1 month, reduced appetite and gross weight reduction. There was history of left ureterolithotomy 4 years back followed by right pyelolithotomy after 2 years.

On clinical examination a mass was palpable in the left half of the thyroid gland.

The laboratory studies on admission were as,

$\begin{array}{ll}\mathrm{HB} & : 12.6 \mathrm{gm} \% \\ \text { Serum Calcium } & : 14.98 \mathrm{mg} / \mathrm{dl} \\ \text { Serum Urea } & : \text { WNL } \\ \text { Serum Creatinine } & : \text { WNL }\end{array}$

Radiograph K-U-B exhibited, bilateral nephrolithiasis computed tomography showed, a well defined $1.7 \times 1.8 \mathrm{~cm}$ soft tissue density, posterior to the left lobe of the thyroid gland. Moreover the left lobe was splayed over it. (Fig. I).

${ }^{1}$ Professor \& Head and Chief, ${ }^{2}$ Senior Lecturer, ${ }^{3}$ Senior Resident, Department of Otorhinolaryngology and Head and Neck Surgery, Dayanand Medical College \& Hospital, Ludhiana - 141001. 


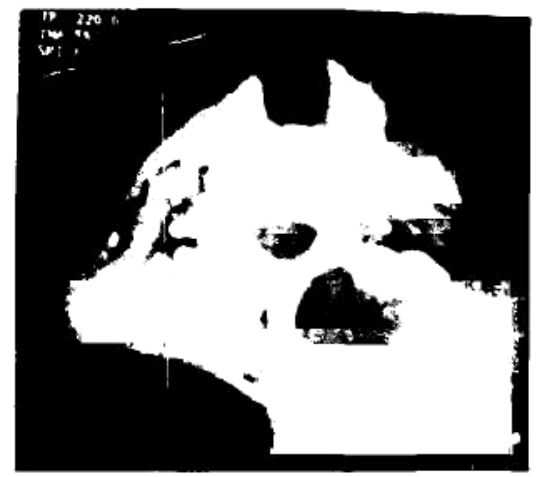

Fig. I : CT scan showing well defined mass in the left thyroid lobe.

\section{MANAGEMENT}

\section{Surgical}

A Hemithyroidectomy along with parathyroid mass excision was carried out under general anaesthesia.

Collar incision as for thyroidectomy was given, the skin flap with platysma raised and a cleavage between the strap muscles and anterior border of thyroid was created. The sternocleidomastoid along with the carotid sheath was retracted laterally and the thyroid gland exposed after ligating the middle thyroid vein. The mass was found within the thyroid gland. No line of cleavage was noted between the mass and the gland. The mass was removed with the left lobe of the gland. The post op phase was uneventful.

The preoperative serum calcium levels ranged between 14.98 to $11.50 \mathrm{mg} / \mathrm{dl}$ and on the 4th post op day fell to $8.77 \mathrm{mg} / \mathrm{dl}$. On the 6th post op day calcium supplementation was started. On the 10th post op day calcium level fell to $6.98 \mathrm{mg} / \mathrm{dl}$.

Histopathology showed a cellular tumor invading the capsule and extending into the surrounding thyroid tissue, consistent with parathyroid carcinoma (Fig.II).

\section{DISCUSSION}

Carcinoma of thyroid gland is suspected clinically if there is a raised serum calcium level, increased parathormone level and a palpable mass in the neck, Diagnosis of parathyroid carcinoma is usually established on pathological criteria of vascular and capsular invasion, gross hyper-parathyroidism and hypercalcemia (Mendoza et al 1997).

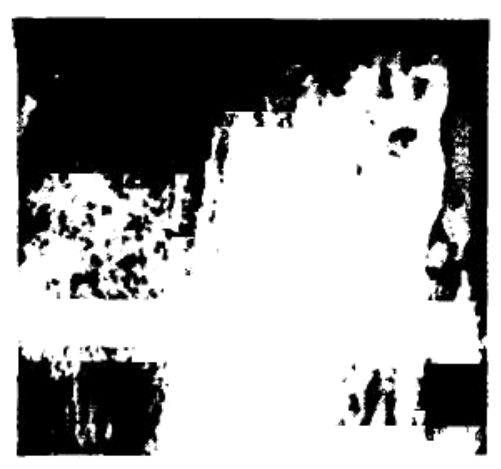

Fig. II : Photomicrograph showing a cellular tumor invading the capsule and adjoining normal thyroid tissue $\mathrm{H}$ and $\mathrm{E}$ stain, $40 \mathrm{X}$ mag.

Severity of symptoms, than parathyroid adenomas is due to gross hypercalcemia (Fyfe et al 1990).

The Mayo's clinic, Wynne study on 43 patients of parathyroid carcinoma, from 1920-1991 recorded polydipsia/polyuria in $38 \%$, myalgia/arthalgia in $27 \%$, asymptomatic patients were $7 \%$, a palpable neck mass was present in $14 \%$ the mean Se Calcium was $14.6 \%$.

Parathyroid carcinoma tend to be large and may be detectable by current imaging modalities. The surgical appearance of these lesions is also distinct, the tumors are frequently multilobulated, greyish in colour firm and often invasive (Mendova V, 1997).

Since the initial surgery offers the best chance of cure, the operation should be enblock resection of the tumour taking care to avoid rupture of capsule and spillage of tumor cells.

Thyroid splaying on CT scan and adherence of parathyroid mass to thyroid lobe clinches the diagnosis of malignancy.

Parathyroid carcinoma is often, undiagnosed preoperatively, suspected intra-operatively and confirmed postoperatively (Samuel et al 1993).

\section{REFERENCES}

1. Fyfe S.T., Hoover L. A., Zuckerbraun L., Goodman M. D., (1990) : Parathyroid carcinoma : Clinical presentation and treatment. American Journal of Otolaryngology. 11 (4) : 268273.

2. Heath H., Hodgson S. R, Kennedy M. A., (1980) : Primary hyperthyroidism : incidence, morbidity and potential econnomic impact in a community. N. Eng. J. Med. 302 : 189 - 193. 
3. Mendoza V., Hernandez A. F., Marguez M. I.,(1997): Primary hyperthyroidism due to parathyroid Carcinoma. Archives of Medical Research. 28 (2) : 303-6.

4. Obara T. I., Okamoto T., Kanbe M., Ihara M.,(1997) : Functioning parathyroid carcinoma. Clinico pathologic features and rational treatment. Seminars in surgical oncology. 13(2) : 134-41.
5. Samuel L. E., Brooks C. E., Karstein M. D., (1993) : Parathyroid Carcinoma. Case report. Military medicine 158(7) 503-4.

6. Wyne A. G., Van Heerdan J., Cavney J. A.. Fitzpatrick. (1992) : Parathyroid carcinoma, clinical and pathological features in 43 patients (Review). Medicine 71(4) : 197205. 